\title{
Women, Apiculture and Development: Evaluating the Impact of a Beekeeping Project on Rural Women's Livelihoods
}

\author{
Cristina Bianca POCOL ${ }^{1 *}$, Molly McDONOUGH ${ }^{2}$ \\ ${ }^{1}$ Department of Economic Sciences, University of Agricultural Sciences and Veterinary Medicine, \\ 3-5, Mănăștur Street, 400372, Cluj Napoca, Romania \\ ${ }^{2}$ Heifer International Romania, 19, Mihai Romanul Street, 400495, Cluj Napoca, Romania \\ *)corresponding author, e-mail: cristina.pocol@usamvcluj.ro
}

BulletinUASVM Horticulture 72(2) / 2015

Print ISSN 1843-5254, Electronic ISSN 1843-5394

DOI:10.15835/buasvmcn-hort:11423

\begin{abstract}
Apiculture is often cited as a possible method of empowering rural women. Beekeeping generates a product with high market potential, while being more easily adapted to constraints of low credit and limited land access than other agricultural activities. Beekeepers in Romania are predominantly male, however studies have shown a growing popularity of the activity among women In 2008 and 2011, Heifer International introduced beekeeping to rural families in Sălaj County, Romania, encouraging equal participation among women and men. By "passing on the gift", the project was also extended in some villages in Cluj county. The goal of the present study was to assess the projects' impact on female beneficiaries several years later. The methodology used was surveying via a quantitative and qualitative questionnaire. The sample size was 30 women, from nine villages of the Someș River Valley involved in the project. The results of the research shown that women continue to practice subsistence farming and beekeeping remains small-scale. However, improvements in household revenues and women's participation are observed. Production is focused mainly on honey, which is sold through informal channels. Women welcome the idea of further diversification through value-added products, and further training to improve market access could provide additional benefits. Families consume more honey and the women acknowledge nutritional benefits. The Heifer principle of "passing on the gift" helped build connections among local women beekeepers. The study offers advice and best practices for future apicultural development projects. It reminds practitioners of the importance of activities that facilitate women's empowerment and agency in rural community development.
\end{abstract}

Keywords: apiculture, Heifer International, impact evaluation, rural, women.

\section{INTRODUCTION}

Beekeeping is often promoted in the context of rural development because the practice provides monetary, nutritional, and social benefits to poor families, without requiring land ownership or large amounts of capital investment (Yap and Devlin, 2015; Wolff et al., 2015). For similar reasons, beekeeping is also cited as a practice that has the potential to empower rural women (Muzaffar 1989; Bradbear et al., 2002; Bhusal and Thapa, 2005). Not only is it more accessible than other forms of agriculture in contexts where women do not have control over household productive aspects such as land; it has also been shown to provide women with additional benefits such as increased community participation and agency (Woldewahid et al., 2012). Beekeeping is an economically profitable activitiy in Romania which is growing in popularity, generating decent incomes for practitioners and high quality products for consumers (Pocol, 2012). Beekeepers in Romania are predominantly male, however studies have shown a growing popularity of the activity among women (Pocol, 2011). Researchers in Africa, Asia and Latin America have explored the roles that women play in beekeeping, but to 
date, there is a lack of gender-specific research regarding this activity in Romania. Studies exploring women's role in beekeeping throughout the world increasingly focus on the obstacles women face in the activity in order to offer suggestions for improvement. Qaiser et al. (2013) and Ejigu et al. (2007) identified barriers to women's participation in beekeeping activities as steps in the process that women, especially young women, are less likely to perform, including colony transfer, queen catching, harvesting and movement of hives. The authors therefore recommend that training sessions are offered which specifically target women. Ogaba (2002) identified similar barriers in Uganda, where women's participation in beekeeping activities is decreased due to a cultural context that limits their control over production assets at the household level. Discussing a development project in Ethiopia, Woldewahid et al. (2012) make a distinction between traditional beekeeping as a supplemental income practice and "market-oriented improved beekeeping," the latter of which focuses more on value chain development and innovation to make the practice a main source of income. Authors found that female-headed households more commonly used the traditional system than the market-oriented system, suggesting that one barrier to entry could be the higher costs of input.

Heifer International is a U.S.-based NGO which cites its mission as working with communities "to end hunger and poverty and care for the Earth," primarily through donating livestock to communities in need (Heifer, 2015). The central philosophy of the 70-year-old charity is "Passing on the Gift": beneficiaries pass on the first female offspring of their livestock to another family. Honeybees are included in Heifer projects as they, like the other animals distributed by the charity, provide families with food as well as reliable income. Along with building social capital, women's empowerment is described as one of the two main "foundational elements" of the Heifer approach (Heifer, 2015). Despite the many programs Heifer has implemented in 128 countries, academic research regarding the evaluation of Heifer programs is lacking in the literature (Pimkina et al., 2013). In 2008, Heifer International and AGAPIS Foundation partnered to introduce beekeeping to families in Salaj County, Romania. They considered that beekeeping represented a solution for households to obtain additional income, due to the fact that starting an apicultural activity does not require a large amount of capital investment compared to other agricultural sectors. This pilot project was expanded in 2011 into a "Honey and Trees" project that included beneficiaries from eight new villages in the Someș Valley in addition to those of Rus commune. Heifer foundation selected families for the project according to the following criteria: level of poverty, knowledge and competency in beekeeping, strong motivation to start an apicultural activity, not being allergic to bees, understanding of Heifer principles, participation in group activities and training sessions. By „Passing on the Gift,” the project was extended to additional families. Both projects encouraged equal participation among women and men. The goal of this study was to assess the impact of the projects, particularly on female beneficiaries, several years later.

\section{MATERIALS AND METHODS}

The study was undertaken in the villages of the Someș River Valley, one of the poorest rural regions of Romania. The research area was represented by nine villages: seven in Sălaj County - Rus, Băbeni, Zalha, Gâlgău, Ileanda, Lozna, Poiana Blenchii - and two in Cluj County - Vad and Câțcău (Fig. 1).

The sample was represented by women belonging to the families involved in the projects. The original goal was to do an exhaustive study with all beneficiaries, thus 52 active beneficiaries

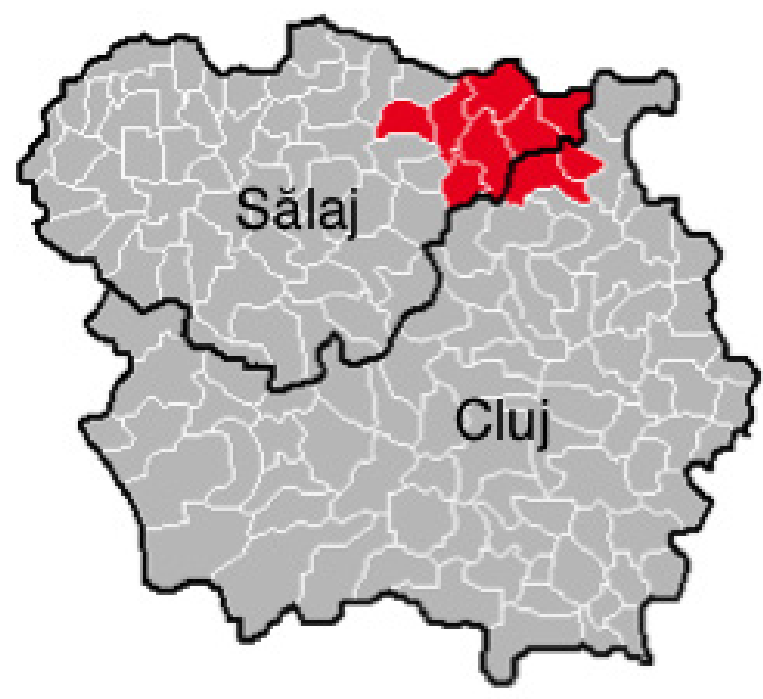

Fig. 1. The research area in Sălaj and Cluj counties 
were contacted. Out of the 52 contacted beneficiaries, 11 were not available, 6 refused to respond and 5 were excluded because they did not have a female in the household. The result was a survey of 30 active project beneficiaries. In order to evaluate the results and the impact of the projects, the women were surveyed via telephone between May 2015 and July 2015, with each questionnaire lasting approximately 30 minutes. The collected data were analyzed using SPSS software. Descriptive statistics (frequencies, cross-tabulation) were used and the results were visually illustrated (tables and graphs).

The survey instrument contained both quantitative and qualitative questions. Quantitative data collected included the number of beehives, experience in beekeeping, products and quantities obtained, marketing channels and involvement in beekeeping tasks. Qualitative data collected included the type of beekeeping practices used, women's perception of the difficulties of beekeeping and of the impact of beekeeping on women's lives. Other qualitative questions included evaluation of training activities, consumption habits and how the project has influenced family nutrition, benefits, motivations and future expectations. Demographic data,

Tab. 1. The distribution of beekeeping farms, under the number of beehives

\begin{tabular}{ccc}
\hline Number of beehives & Frequency & Percent $\%$ \\
\hline Maximum 10 beehives & 2 & 7.00 \\
\hline Between 11-50 beehives & 19 & 63.00 \\
\hline Between 51-80 beehives & 5 & 17.00 \\
\hline Between $81-150$ beehives & 4 & 13.00 \\
\hline Over 150 behives & 0 & 0.00 \\
\hline Total & 30 & 100.00 \\
\hline
\end{tabular}

such as gender, age, education, occupation and household revenues were also collected.

\section{RESULTS AND DISCUSSION}

The project contributed five initial hives to each family, and since the implementation most families have increased that number to between 11 and 50 hives. Considering the threats related to bee mortality and the fact that all families had to "pass on the gift" to new households, this represents progress. The beneficiaries who represent the largest increase in hives (from 81 to 150 hives) are those who transformed the family activity into a business through association of multiple households (Tab. 1).

The majority of respondents have only started beekeeping in the last five years. It should be noted that all respondents began beekeeping as part of the project even if they had some years of experience in the past, for example, beekeeping activities during childhood (Tab. 2).

Stationary beekeeping is the most common, practiced by $70 \%$ of respondents. The main reason cited for remaining stationary is a lack of time and resources; beekeeping is usually a secondary activity, and transhumant beekeeping requires authorization as well as additional costs (transport, bee truck, etc).

Tab. 2. Experience in beekeeping

\begin{tabular}{ccc}
\hline Number of years & Frequency & Percent $\%$ \\
\hline Maximum 5 years & 20 & 66.00 \\
\hline Between 6-10 years & 6 & 20.00 \\
\hline Between 11-15 years & 2 & 7.00 \\
\hline More than 15 years & 2 & 7.00 \\
\hline Total & 30 & 100.00 \\
\hline
\end{tabular}

Fig. 2. Level of education (last graduated school) 
Regarding the respondents' level of education a high level of human capital involvement in the project can be observed (Fig. 2). Research by Qaiser et al (2013) on beekeeping in Pakistan also noted that women partaking in beekeeping projects tended to have higher levels of education; this could suggest that education is related to the motivation and agency to undertake this new activitity. Many beekeeping women surveyed are also employed outside of their homes; in this case, perhaps apiculture offers an additional opportunity to supplement income and food, making their households more resilient against the threat of unemployment.

All respondents declared that they produce honey, while the second most popular marketed product is pollen (propolis remains for selfconsumption and wax is used primarily for exchange into artificial combs). Only one respondent declared that her household produces queens for selling. Honey production typically fluctuates from one year to another depending on climatic conditions. 2014 was, in general, a bad year in Romania for apicultural production. Due to the drought, the harvested honey production has decreased dramatically, from 26678 tones in 2013 to 18040 tones in 2014 (National Institute of Statistics, 2015).

The quantity of harvest reported by project beneficiaries reflect this trend; honey obtained varies from 5 to $10 \mathrm{~kg}$ /year per hive. $17 \%$ of respondents have encountered specific difficulties related to beekeeping, such as artificial bee reproduction and the production of venom and royal jelly. The majority of products are consumed within households and exchanged informally among extended family. Even if products are sold, informal channels are most often used (friends, relatives, neighbors etc). The honey is rarely sold in the marketplace or to intermediaries.

Regarding the involvement of women in beekeeping, one can identify two main categories of women beekeepers. The first consists of women who work independently in their beekeeping activities without requiring help from a male in the household ( $1 / 3$ of respondents). The second group is represented by women who work alongside male family members (usually husbands) in the beekeeping activity.

Women who exhibit independence in beekeeping activities sometimes acknowledge that beekeeping has its difficulties, such as transporting heavy hives. But for these women the benefits appear to compensate for the obstacles; according to one beneficiary, beekeeping gives her a satisfaction that makes up for difficult moments. Several of them compare beekeeping to other agricultural activities, saying that it's easier than raising livestock, and that bees are smaller and less time-consuming (one does not have to be at home everyday to feed them). Still others cite the compatibility of beekeeping with women's abilities and character, saying that women benefit from a higher level of precision, patience and the willingness to work meticulously. Many women appear to see beekeeping as compatible with their other roles in the household, such as raising children; one described the importance of including her handicapped son in the activity. One beneficiary described the way in which she has learned from the bees themselves, saying that they have inspired her as a model for how to work to keep her household clean and organized. Others described the practice as an „art” and express pride in their accomplishments, suggesting that the benefits extend beyond the material goods obtained. The importance of these additional benefits of beekeeping has also been discussed by Shackleton et al. (2011), who point out that analysis „must not only assess women's control over conventional economic resources," but must also examine aspects related to increased choice and dignity.

The second group of women who work together with males in beekeeping activity cite positive aspects of women's role as well as its limits. Some believe that a woman's success in beekeeping is dependent on her character traits: for example, she must have courage, she must be calm, or she must be organized in other aspects of life (such as having a clean household). One beneficiary described seeing other countries where women between 30 and 70 years of age were more involved in beekeeping than in Romania (Poland and Belgium). Another considered that women in their village were too old to begin beekeeping activities. Some believe that the woman requires help from an experienced male beekeeper when beginning, or that women need help introducing new equipment.

Others consider that only stationary beekeepingisappropriateforwomen; transhumant 
beekeeping requires movement away from the household and thus is not compatible with women's traditional household role. This obstacle echoes the constraint identifed by Shackleton et al. (2011) among women beekeepers in Africa, who are limited by their obligations in the household and as caregivers, and thus cannot partake in activities outside of the home.

$43 \%$ of households report men being the primary honey product consumer. The majority have said that men consume honey either a) to gain energy when they feel tired, b) before breakfast for therapeutic purposes (mixed with pollen and propolis), and c) to sweeten tea, coffee and țica (traditional plum brandy). 20\% of households report women and children being the primary honey product consumers, with uses most often cited including a) for breakfast, and b) as a sweetener in cooking (not only for desserts such as cakes and sesame-honey sticks, but also for pickling vegetables and making zacusca, a traditional Romanian vegetable food). $37 \%$ of households reported equal consumption of honey among all family members, in similar ways. In general the beneficiaries perceive honey and other bee products to be natural and healthy, having an essential role in their diet. Some families even report using bees and honey for medical purposes, such as bee stings to treat rheumatism and honey and other products for stomach problems, the flu, etc.

The project had an impact on the consumption habits of the families, who reported not having consumed much honey at all before they began producing it themselves. Honey was not as accessible before the project, not only in financial terms but in physical terms; in 2008, there was about one beekeeper per commune with 10-30 hives. Families reported replacing other products such as sugar with honey, or replacing eggs and bacon at breakfast with bread, butter and honey. Families report having confidence in the authenticity of their own products, preferring to product it themselves instead of purchase from the supermarket.

$83 \%$ of households would like to increse their number of bee families. Four families would like the number of hives to remain constant (between 81 and 150 beehives). Only one of the respondents wants to renounce to beekeeping in the future, being dissapointed with, or not understanding, the bees' mortality.
While the health of the family remains the most important reason to continue and increase beekeeping activities for the women, the possibility of increased revenues was also cited as a motivating factor. In the frame of the project, AGAPIS and the Association of Intercommunity Development of the Someș Valley supported the beneficiaries by organizing qualitative and technical training sessions. These sessions helped participants commence beekeeping activity, but to learn more about marketing and find additional support, some participants sought other training courses outside of the frame of the project (in Cluj, Zalău or Baia Mare or through the Local Action Group of the Someș Valley). Some beneficiaries describe efforts to promote their products abroad, such as through family members who live in other EU countries (France, Denmark). Interestingly, those who express interest in selling products abroad still use only the informal market; this may suggest that the women would benefit from additional training in marketing. The solution could also lie in collective action; Chen et al (2004) echo that women are often left out of the formal market because of the small size of their enterprise and lack of resources. One solution for informal honey producers in reaching the export market, authors argue, is the presence of a social entrepreneur to organize the producers collectively.

Other reasons for continuing beekeeping include being out in the fresh air, becoming more responsible, help with pollination, being old and not able to partake in more difficult agricultural activities. For almost all beneficiaries, beekeeping remains a secondary activity for the moment, although some expressed interest in making it a primary activity later on-when their children are old enough to help them, or when they are retired from their jobs. The lack of time to focus on increasing the beekeeping activity is thus an obstacle to increased economic returns.

An important aspect of beekeeping is the effect it has had on facilitating women's community involvement through exchanges of experience and meeting new people. This can represent important progress in Romania where associative forms of agriculture struggle to gain hold (Rahoveanu et al., 2012). Promoting the association of female beekeepers could offer additional benefits, however around the world, results of women's collective beekeeping ventures have been mixed. 
Evaluating the failure of a women's beekeeping association in central Iran, Alirezanejad (2011) found that beekeeping was more successful as a form of personal empowerment than collective empowerment, women preferring to re-invest profits back into their own households for the well-being of their husbands and children rather than into the association. Exploring the ways in which women are empowered at the household versus at the community level through beekeeping thus represents an interesting pathway for further research.

\section{CONCLUSION}

The research highlights several positive effects of the Heifer International/AGAPIS project on the local communities. Since the project began, nearly all beneficiaries have increased their number of hives and many are making a range of honey products. Analyzing the effects of the project on women, the most notable impacts appear to be noneconomic and are rather related to independence, community/social aspects, and general feelings of pride and well-being. Women also see honey production as a way to supplement household foods (i.e. by replacing sugar) and contributing to positively to family nutrition. Despite their positive outlook towards beekeeping, the majority of women do not perform the activities alone but rather in conjunction with their husbands or other male family members. Constraints regarding time and mobility discourage many project beneficiariesespecially women-from scaling up production or orienting products towards the formal market. Training focused on marketing skills could help to increase the economic benefits of beekeeping, but it should be noted that the informal cooperation of community members surrounding honey production and exchange seems to have the potential to offer additional benefits.

Acknowledgments. Authors wish to thank Heifer International Romania, AGAPIS Foundation and Association of Intercommunity Development of the Someș Valley for their support and collaboration.

\section{REFERENCES}

1. Alirajanejad S (2011). Uneven Empowerment: a case study on women beekeepers in Central Iran. International Journal of Social Sciences 1(2): 145-157.
2. Bhusal SI, Thapa RB (2005). Comparative study on the adoption of improved beekeeping technology for poverty alleviation. Journal of the Institute of Agriculture and Animal Science. 26: 117-125.

3. Bradbear N, Fisher E, Jackson H (2002). Strengthening livelihoods: exploring the role of beekeeping in development. Bees for Development.

4. Chen MA, Vanek J, Carr M (2011). Mainstreaming informal employment and gender in poverty reduction: a handbook for policymakers and other stakeholders. Commonwealth Secretariat.

5. Ejigu K, Agdaba N, Bekele W (2007). The role of women and indigenous knowledge in Ethiopian beekeeping. Bees for Development Journal 86: 4-6.

6. Heifer International (2015). About Heifer International. Retrieved 17.7.2015 from www.heifer.org.

7. Muzaffar N (1989). Beekeeping_an income generating cottage industry for rural women in Pakistan. In Proceedings of the Fourth International Conference on Apiculture in Tropical Climates. Cairo.

8. National Institute of Statistics (2015). Animal agricultural production by ownership form, macroregions, development regions and counties. Retrieved 11.10.2015 from http://statistici.insse.ro.

9. Ogaba M (2002). Household poverty reduction through beekeeping amongst Uganda rural women. Standing Commission of Beekeeping for Rural Development, Monmouth.

10. Pimkina S, Rawlins R, Barrett CB, Pedersen S, Wydick B (2013). Got Milk? The Impact of Heifer International's Livestock Donation Programs in Rwanda. Food Policy 44: 202-213.

11. Pocol CB (2011). Resources and models of beekeeping exploitations in the North West region of Romania. Bulletin UASVM Horticulture 68(2): 180-187.

12. Pocol CB (2012). Analysis of production and sales of bee products in the north of Transylvania. Lucrari Stiintifice Seria I. 14 (2):263-270.

13. Qaiser T, Murad A, Taj S, Akmal N (2013). Impact Assessment of Beekeeping in Sustainable Rural Livelihood. Journal of Social Sciences 2(2): 82-90.

14. Rahoveanu MM, Turek Rahoveanu A, Cristea L (2012). Prospects for agricultural cooperatives in the context of CAP reform 2014-2020. Scientific Papers Series Management, Economic Engineering in Agriculture and Rural Development.

15. Shackleton S, Paumgarten F, Kassa H, Husselman M Zida M (2011). Opportunities for enhancing poor women's socioeconomic empowerment in the value chains of three African non-timber forest products (NTFPs). International Forestry Review 13(2): 136-151.

16. Woldewahid G, Gebremendhin B, Hoekstra D, Tegegne A, Berhe K, Weldemariam D (2012). Market-oriented beekeeping development to improve smallholder income: Results of development experiences in Atsbi-Womberta district, northern Ethiopia. Nairobi: International Livestock Research Institute (ILRI).

17. Wolff LF, Gomes JJC (2015). Beekeeping and Agroecological Systems for Endogenous Sustainable Development. Agroecology and Sustainable Food Systems 39(4): 416435.

18. Yap NT, Devlin JF (2015). Beekeeping innovation for sustaining rural livelihoods. A success story. Innovation and Sustainable Development 9(2) 103-117. 